\title{
INCIDENCE OF CAMPYLOBACTER SPECIES IN LAYING HENS AND TABLE EGG IN SOHAG GOVERNORATE
}

\author{
KH.A.A. HEDAWEY and AMANY A. YOUSSEF \\ * Dept.of Microbiology. Animal Health Research Institute, Sohag Regional Laboratory, Dept. of Poultry Diseases \\ Email: khaledhedawy@yahoo.com
}

\section{ABSTRACT}

Received at: 19/3/2014

Accepted: 5/5/2014
A Total of 200 samples (100 cloacal swabs and 100 of eggs from laying farms) were collected in Sohag Governorate. The samples were examined for the presence of Campylobacter. The bacteriological examination revealed isolation of 38 isolates of Campylobacter species from cloacal swabs (25 isolates $(65.8 \%)$ of $C$. jejuni and 13 isolates $(34.2 \%)$ of $C$. coli). On the other hand one isolate (1.0\%) from egg shell was isolated. While trial of isolation from egg content was unsuccessful. Concerning experimental infection of chickens with C. Jejuni, the mortality rate, was $(30.0 \%)$ among chickens infected intramuscularly, while it was $(20.0 \%)$ after oral infection .On the other hand the infection with $C$. coli revealed that mortality rate, was $(20.0 \%)$ among chickens infected $\mathrm{I} / \mathrm{M}$ and $(10.0 \%)$ after oral infection. In vitro sensitivity test, most isolates were highly sensitive to spiramycin, spectinomycin, clindamycin, gentamycin and colistin sulphate and were resistant to amoxicillin and penicillin.

Key words: Campylobacter Jeguni, coli, chicken breeder, eggs.

\section{INTRODUCTION}

Campylobacter species are Gram- negative, spiral and or curved non spore forming, $0.2-0.9 \mu \mathrm{m}$ wide and 0.5- $5.0 \mu \mathrm{m}$ long. They are oxidase positive with one polar flagellum at one or both ends giving a corkscrew - like motility (Bolton et al.; 1992). Although eggs have a high nutritive value, it may be responsible for several outbreaks and acts as a vehicle for transmission of pathogens to consumers (Hangombe et al.; 1999 and Gast et al.; 2004). Sources of egg contamination are numerous such as eggs may become infected before they are laid at the genital system of birds, when the ovary is infected with bacterial pathogens. After laying, the shell soon become contaminated with a variety of organisms by faecal matter from the bird, contact with dirty surfaces, food stuffs, by washing water, by handling, or perhaps by accumulation of eggs (DeReu et al.; 2008). In poultry, C Jejuni is responsible for avian vibrionic hepatitis which is a contagious disease of young and mature chickens characterized by low mortality, high morbidity associated with chronic course, poor growth and production (Peckham, 1984). Also, poultry was considered a major reservoir for human Campylobacteriosis, so reduction or elimination of poultry contamination with $C$. jejuni would greatly reduce the risk of campylobacter for public health (Park, 2002). Toxic infections caused by microorganisms of the Campylobacter genus are food borne diseases. The primary source of which are poultry and poultry products (Corry and Atabay,
2001). The microorganism is microaerophilic and the percentage of oxygen in the atmosphere is toxic to it, so the cultures should be maintained under reduced oxygen tension. A satisfactory mixture is $(5.0 \%) \mathrm{O} 2$, $10.0 \%) \mathrm{CO} 2$ and $(85.0 \%) \mathrm{N}$ (Leuchtefeld and Wang, 1981). Although critical control measures for the safety of food regarding the health of the consumer had been introduced, serious health hazards outbreaks due to consumption of the eggs still persisted. So the aim of this work is to investigate the incidence of campylobacter species which may be found in laying hens and table eggs in Sohag Governorate.

\section{MATERIALS and METHODS}

\section{1- Samples:}

A total of 200 samples (100 cloacal swab of poultry farm with 16 weeks old and 100 of eggs) were collected in Sohag Governorate. The collected samples were packed in box and aseptically transferred to the laboratory without delay where they were immediately examined bacteriologically.

\section{2- Bacteriological examination:}

The cultivation of samples were carried out in Bolton broth supplement with antibiotic (oxoid) Bolton et al. (1992) and gently shaken for $5 \mathrm{~min}$. The mixture was subjected to micro aerophilic with resuscitiation $4 \mathrm{hrs}$ at $25-42{ }^{\circ} \mathrm{C}$ followed by $40-44 \mathrm{hrs}$ at 25 and $42{ }^{\circ} \mathrm{C}$. The subculture onto Modified Charcoal Cefoperazone Desoxycholate Agar (MCCDA) (Oxoid) and blood agar was carried out. The samples were incubated in 
micro aerobic atmosphere $25^{\circ} \mathrm{C}$ and $42{ }^{\circ} \mathrm{C}$ for $48-72$ hrs. Bacterial colonies that exhibited cellular, colonial and biochemical characteristic were observed according to Bolton et al. (1992).

\section{3- Experimental infection:}

A total of fifty five, one month old chicks obtained from private farms, Sohag Governorate were used to study the pathogenicity of Campylobacter species. Before infection, a random sample which included 5.0 chicks were sacrified for postmortem and bacteriological examination to prove that these chicks were healthy. The other chicks were divided into 5.0 groups, each of 10.0 chicks. The first group was infected orally with $0.5 \mathrm{ml}$ of $1 \times 10^{8}$ colony forming unite adjusted by Macferland density technique of viable identified organism (Finegold and Martin, (1986) of $C$. jejuni for two successive days. The second group was inoculated IIM with $0.5 \mathrm{ml}$ of $1 \times 10^{8}$ cfu of $C$. jejuni. The third group was infected orally with $0.5 \mathrm{ml}$ of $1 \times 10^{8} \mathrm{cfu}$ of $C$. coli for two successive days. The fourth group was inoculated $1 / \mathrm{M}$ with $0.5 \mathrm{ml}$ of $1 \times 10^{8} \mathrm{cfu}$ of C.coli. The fifth group was left as uninfected control. All chicks were kept under observation, symptoms and postmortem finding were recorded.

\section{4 - In vitro - Sensitivity test:}

The isolated $C$. jejuni and $C$. coli strains were examined for their susceptibility to the different antibiotics. The paper discs were supplied by BioMerieux and Oxoid namely, Spiramycin (10.0mg), Colistin sulphate (10.0 ug), Enrofloxacin (10.0 ug), Gentamycin (10.0 ug), Penicillin (10.0 I.U), Amoxicillin (25.0 ug), Clindamycin (100.0 ug), Spectincmycin (100.0 ug), Neomycin (30.0 ug), Oxytetracyclin (30.0 ug), Ampicillin (10.0 ug) and Streptomycin (10.0 ug). The discs diffusion technique of sensitivity to different chemotherapeutic agents was done according to (Finegold and Martin, 1986).

\section{RESULTS}

Table 1: The Incidence of Campylobacter species recovered from diseased chickens and eggs.

\begin{tabular}{cccc}
\hline Examined samples & No. of sample & \multicolumn{2}{c}{ Positive cases } \\
\cline { 3 - 4 } & & No. & 38 \\
\hline Cloacal swabs & 100 & 38 & 1 \\
\hline Egg shell & 100 & 1 & 0 \\
\hline Egg content & 100 & 0 & 0 \\
\hline
\end{tabular}

Table 2: The frequency of Campylobacter species recovered from diseased chickens and eggs.

\begin{tabular}{cccccc}
\hline Examined samples & \multirow{2}{*}{$\begin{array}{c}\text { Total number } \\
\text { of isolates }\end{array}$} & \multicolumn{5}{c}{ Campylobacter species } \\
\cline { 3 - 6 } & & \multicolumn{2}{c}{ C. jejuni } & C. coli \\
\cline { 3 - 6 } & & No. & $\%$ & No. & \% \\
\hline Cloacal swabs & 38 & 25 & 65.8 & 13 & 0 \\
\hline Egg shell & 1 & 1 & 100 & 0 & 0 \\
\hline Egg content & 0 & 0 & 0 & 0 & 0 \\
\hline
\end{tabular}

Table 3: The biochemical characterization of Campylobacter isolate strains.

\begin{tabular}{ccccccc}
\hline Isolate strains & oxidase & catalase & nitrate reduction & H 2 S on tsi & growth of \\
\cline { 3 - 6 } & & & & & $25 \mathrm{C}^{\circ}$ & $42 \mathrm{C}^{\circ}$ \\
\hline C. jejuni & + & + & + & $\mathrm{V}$ & - & + \\
\hline C. coli & + & + & + & $\mathrm{V}$ & + & + \\
\hline
\end{tabular}


$\underline{\text { Assiut Vet. Med. J. Vol. } 60 \text { No. } 141 \text { April } 2014}$

Table 4: The results of experimental infection of chicks with Campylobacter species.

\begin{tabular}{|c|c|c|c|c|c|c|c|c|c|c|c|c|c|c|}
\hline \multirow{2}{*}{$\begin{array}{l}\text { Group } \\
\text { no. }\end{array}$} & \multirow{2}{*}{$\begin{array}{c}\text { No . of } \\
\text { infected } \\
\text { bird }\end{array}$} & \multirow{2}{*}{$\begin{array}{c}\text { Route of } \\
\text { inoculation }\end{array}$} & \multicolumn{9}{|c|}{ Daily death post infection } & \multicolumn{2}{|c|}{$\begin{array}{l}\text { Total no. } \\
\text { of death }\end{array}$} & \multirow{2}{*}{$\begin{array}{c}\text { Mortality } \\
\text { rate }\end{array}$} \\
\hline & & & 1 & 2 & 3 & 4 & 5 & 6 & 7 & 8 & 9 & 10 & & \\
\hline 1 & 10 & orally & - & - & - & - & - & 1 & - & 1 & - & - & 2 & $20 \%$ \\
\hline 2 & 10 & $\mathbf{I} / \mathbf{M}$ & - & - & 1 & - & 1 & 1 & - & - & - & - & 3 & $30 \%$ \\
\hline 3 & 10 & orally & - & - & - & - & - & 1 & - & - & - & - & 1 & $10 \%$ \\
\hline 4 & 10 & $\mathbf{I} / \mathbf{M}$ & - & - & 1 & - & 1 & - & - & - & - & - & 2 & $20 \%$ \\
\hline 5 & 10 & control & - & - & - & - & - & - & - & - & - & - & - & $0 \%$ \\
\hline
\end{tabular}

Group 1 and 2 infected orally and injected I / $\mathrm{M}$ with $C$. Jejuni

Group 3 and $4=$ infected orally and injected I / $\mathrm{M}$ with $C$ coli

Table 5: Demonstrates the results of in- vitro sensitivity test.

\begin{tabular}{ccc}
\hline Antimicrobial agent & C. jejuni & C. coli \\
\hline Spiramycin & +++ & +++ \\
\hline Colistin sulphate & +++ & ++ \\
\hline Enrofloxacin & ++ & + \\
\hline Gentamycin & +++ & +++ \\
\hline Penicillin & - & - \\
\hline Amoxicillin & - & - \\
\hline Clindamycin & +++ & ++ \\
\hline Spectincmycin & +++ & +++ \\
\hline Neomycin & ++ & ++ \\
\hline Oxytetracyclin & + & + \\
\hline Ampicillin & + & + \\
\hline Streptomycin & + & + \\
\hline
\end{tabular}

$+++=$ Highly Sensitive

$++=$ Moderately Sensitive

$+=$ Weakly Sensitive

- $\quad=$ Resistant

\section{DISCUSSION}

Until recently, Little was known regarding bacterial contamination of table eggs. The shell can already be infected when passing through the vent. It is hypothesised that bacterial contamination of the egg content could result from the penetration of the shell by bacteria deposited on the surface of the egg after it has been laid (Messens et al., 2007).

Campylobacter Jejuni and coli has become recognized as a common aetiological agent in human diarrhea. These microorganism are wide spread in broiler farms (Wieliczko, 1995.a). 
As shown in Table (1) the bacteriological examination of 100 cloacal swabs revealed the prevalence of Campylobacter species in a total percentage of $(38 \%)$. On the other hand Campylobacter species was isolated from egg shell with an incidence of (1\%) while egg content samples were negative for the isolation of Campylobacter species.

Regarding to Table (2), the frequency of Campylobacter species recovered from diseased chicken and eggs shown that 25 isolates were Campylobacter jejuni (65.8\%) and 13 isolates of Campylobacter coli with and incidence of (34.2\%).

On the other hand, Campylobacter jejuni was isolated by (1\%) from egg shell but could not isolate Campylobacter jejuni and coli from egg content. These results were similar to those recorded by (Lin, 1988; Ahmed and Ahmed, 1994, Adesiyun et al.; 1994; Vashin et al.; 2008 and Messelhausser et al.; 2011).

A higher percentage of Campylobacter species were found in the cloacal swab and lower incidence in egg and its contant perhapas vertical transmission of C.jejuni and C.coli through the egg is probably a rare event and does not play a major role in the transmission of Campylobacter on poultry farms.

Biochemical characterization of the isolated Campylobacter species was found to be oxidase and catalase positive, reduced nitrates to nitrites, produced no acid in triple suger iron agar and was $\mathrm{H} 2 \mathrm{~S}$ positive by lead acetate paper strips.

C.jejuni growth occurred at $42^{\circ} \mathrm{C}$ but not at $25^{\circ} \mathrm{C}$ while C.coli can grow at $25^{\circ} \mathrm{C}$ and $42^{\circ} \mathrm{C}$ (Table 3). The experimental infections in chickens with C.jeuni and C.coli via orally and intramuscularly revealed that, as shown in (Table 4), C.jejuni produced 30.0\% and $20 \%$ mortalities when inoculated I/M and orally respectively. On the other hand C.coli produced $20.0 \%$ and $10.0 \%$ when inoculated $\mathrm{I} / \mathrm{M}$ and orally respectively. These results agreed with those obtained by (Ruiz - palacois et al., 1981; Sayed, 2000; Nagla, 2005; Sahin et al., 2003) and Nor et al., 2013).

The results of anti microbial sensitivity test for C.jeguni and C.coli isolates revealed that C.jeguni isolates were highly sensitive to spiramycin, colistin sulphate, gentamycin, clindamycin and spectinomycin. Similar results were recorded by Sayed, 2000); Schwaiger et al.; 2008); and DeReu et al., 2008) and Nor et al., 2013). On the other hand, C.coli isolate were highly sensitive to spiramycin, gentamycin and spectinomycin while resistant to Ampicillin, penicillin and amoxicillin. These are in accordance with the results obtained by (Ge et al., 2003; Wilson, 2003; Ronner et al., 2004; Schwaiger et al., 2008 and Nor et al., 2013).
From this study we concluded that the capability of Campylobacter species to interior and /or survive within the egg is quite limited, therefore, it is probable that vertical transmission is an unusual event in breeder hens, and that there are other infection route, moreover future researches using molocular biology must be conducted in an attempt to demonstrate viable non. culturable cells of Campylobacter species inside eggs.

\section{REFRENCES}

Adesiyun, A.A.; Ojo, M.O.; Mohammed, K. and Garcia, G. (1994): Frequency of isolation of Campylobacter and Samonella from live broilers reared by contact farmers in Trindad. Bulletin of Animal Health and production in Africa. 42(3): 167-172.

Ahmed, M.M. and Ahmed, F.A. (1994): Occurrence of Campaylobacter species in broilers and laying hens suffering from diarrhea. Ass. Vet. Med. J. 32 (63): 119-125.

Bolton, F.J.; Wareing, D.R.A.; Skirrow, M.B. and Hutchimson, D.N. (1992): Identification and biotyping of Campylobacter. In Identification Methods in Applied and Environmental Microbiology ed. Board, R.G; Jones, D. and Skinner, F.A. PP. 151-161 Oxford: Black Wdl Scientific Publication.

Corry, J.E.L. and Atabay, H.I. (2001): Poultry as a source of Camplylobacter and related organisms. Journal of Applied Microbiology. 90, 96s- $114 \mathrm{~s}$

DeReu, W.; Messens, M.; Heyndrickx, T.B.; Rodenberg, M. and Uyttendaele and Herman, L. (2008): Bacterial contamination of table eggs and the influence of housing systems. Worlds Poultry Science Journal, Vol. 64. 5-19.

Finegold, M. and Martin, E.J. (1986): Diagnostic Microbiology. 7th Ed. P.P. 186. The C.V. Mosby Company. St. Louis. Torento. London.

Gast, RK.; Guardo Bouldin, J. and Holt, Ps. (2004): Colonization of reproductive organs and internal contamination eggs after expriemental infection of laying hens with Salmonella heidelberg and Salmonella enteritidis. Avian Dis. 48(4): 863-869.

Ge, B.; White, D.G.; Mc-Dermatt, P.F.; Girard, W.; Zhao, S.; Hubert, S. and Meng, J. (2003): Antimicrobial resistant Campylobacter species from retail raw meats. App .Environ-Microbial 69(5): 3005-3007.

Hangombe, B.M.; Sharma, R.N.; SKjerver, E. and Tuchili, L.M. (1999): Occurance of Salmonella enteritidis in pooled table eggs and marketready chicken carcasses in Zambia. Avian Dis. 43 (3): 597-599.

Leuchtefeld, N.A.W. and Wang, W.L. (1981): J. Clin .Microbial 13: 266-268. 
Lin, Y.J. (1988): Survey for Campylobacter fetus subspecies. jejuni infection in domestic fowls in Fujian province Chinese J. Vet. Sci. and Technol 6: 18-20.

Messelhausser, U.; Tharigen, D.; Elmer-Englhard, D.; Bauer, H.; Schreiner, H. and Hollar, C. (2011): Occurance of thermotolerant Campylobacter spp. On egg shell: a Missing link for food-Borne infection?.

Applied and Enviromental Microbiolagy (2011) p $3896-97$.

Messens, W.; Grijspeerdt, K.; De Reu, K.; Deketelaere, B.; Mertens, K.; Bamelis, F.; De Baerdemaker, J.; Decuypere, E. and Herman, L. (2007): Egg shell penetration of various types of hens egg by various micro organisms. Journal of Food Protection 70: 623-628.

Nagla, F. (2005): A study on Campylobacter species in chickens In EL-Fayoum Governorate. M.V.SC. Thesis of Microbiology Fac. Vet. Med. Ben-Suef. Univerisity.

Nor, F.S.; Saleha, A.A.; Jalila, A. and Fauziah, N. (2013): Occurrence of Campylobacter and Salmonella in ducks and duck eggs in Selangor. Malaysia Tropical Biomedicine 30 (1): 155-158.

Park, S.F. (2002): The physiology of Campylobacter species and its relevance to their role as food borne pathogens. International Journal of Food Microbiology 74, 177-188.

Peckham, M.C. (1984): Avian vibrio infecions in M.S. Hofstad, H.J. Barnes, B.W. Calvek, W.M. Reid and H.W. Yoder, Jr. (eds) disease of poultry, $8^{\text {th }}$ ED . PP. 221-231. Iow State Univ. Press Ames.

Ronner, A.C.; Engvall, E.O.; Andersson, L. and Kaijser, B. (2004): Species identification by genotyping and determination of antibiotic resistance in Campylobacter jejuni and Campylobacter coli from humans and chickens in Sweden. Int. J. Food. Microbiol. 1-96(2) 173-179.

Ruiz-palacois, G.M.; Escamilia, E. and Torres, N. (1981): Experimental Camplylobacter diarrhea in chickens.Infect-Immunol. 34 (1): 250-255.

Sahin, O.; Kobalka, P. and Zhang, Q. (2003): Detection and survival of Campylobacter in chicken eggs. Journal of Applied Microbiology 95: 1070-1079.

Sayed, A.M. (2000): Campylobacter infection in boiler chickens in Assiut. J. Assiut. Vet. Medic. 42(84) 213-221.

Schwaiger, K.; Schmied, FM. and Bauer, J. (2008): Comparative analysis of antibiotic resistance characteristics of Gram-negative bacteria isolated from laying hens and eggs in conventional and organic keeping systems in Bavaria, Germany Zoonoses Public Health 55 (7): 331-341.

Vashin, I.; Stoyanchev, T. and Roussev, V. (2008): Prevalence of microorganism of the Campylobacter genus in Quail (Coturnix Coturnix) eggs. Bulgarian Journal of Veterinary Medicine. 11(3): 213-216.

Wieliczko, A. (1995.a): The role of Campylobacter in poultry pathology. Part 1. Epidimiological studies on Campylobacter infections in poultry. Medycyna Weterynaryina.51 (3): 150-152.

Wilson, I.G. (2003): Antibiotic resistance of Campylobacter in raw retail chickens and imported Chicken portions Epidemiol. Infect. 131(3): 1181- 1186.

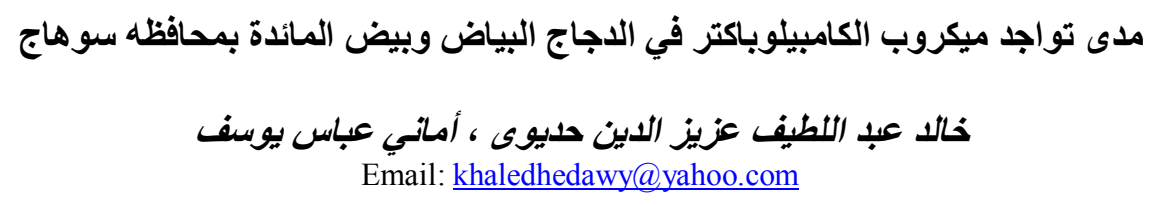

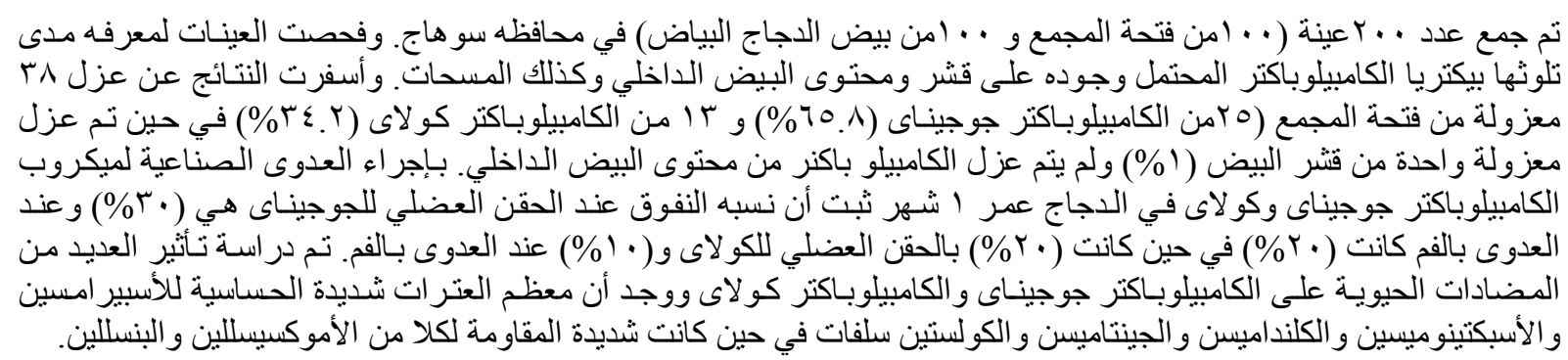

